\title{
RNA Catalysis in Model Protocell Vesicles
}

\section{Citation}

Chen, Irene A., Kourosh Salehi-Ashtiani, and Jack W. Szostak. 2005. "RNA Catalysis in Model Protocell Vesicles." Journal of the American Chemical Society 127 (38): 13213-13219. doi:10.1021/ja051784p. http://dx.doi.org/10.1021/ja051784p.

\section{Published Version}

doi:10.1021/ja051784p

\section{Permanent link}

http://nrs.harvard.edu/urn-3:HUL.InstRepos:29408327

\section{Terms of Use}

This article was downloaded from Harvard University's DASH repository, and is made available under the terms and conditions applicable to Other Posted Material, as set forth at http:// nrs.harvard.edu/urn-3:HUL.InstRepos:dash.current.terms-of-use\#LAA

\section{Share Your Story}

The Harvard community has made this article openly available.

Please share how this access benefits you. Submit a story.

Accessibility 


\title{
RNA Catalysis in Model Protocell Vesicles
}

\author{
Irene A. Chen, Kourosh Salehi-Ashtiani, and Jack W. Szostak* \\ Contribution from the Howard Hughes Medical Institute and Department of Molecular Biology, \\ Massachusetts General Hospital and Department of Genetics, Harvard Medical School, \\ Boston, Massachusetts 02114
}

Received March 21, 2005; E-mail: szostak@molbio.mgh.harvard.edu

\begin{abstract}
We are engaged in a long-term effort to synthesize chemical systems capable of Darwinian evolution, based on the encapsulation of self-replicating nucleic acids in self-replicating membrane vesicles. Here, we address the issue of the compatibility of these two replicating systems. Fatty acids form vesicles that are able to grow and divide, but vesicles composed solely of fatty acids are incompatible with the folding and activity of most ribozymes, because low concentrations of divalent cations (e.g., $\mathrm{Mg}^{2+}$ ) cause fatty acids to precipitate. Furthermore, vesicles that grow and divide must be permeable to the cations and substrates required for internal metabolism. We used a mixture of myristoleic acid and its glycerol monoester to construct vesicles that were $\mathrm{Mg}^{2+}$-tolerant and found that $\mathrm{Mg}^{2+}$ cations can permeate the membrane and equilibrate within a few minutes. In vesicles encapsulating a hammerhead ribozyme, the addition of external $\mathrm{Mg}^{2+}$ led to the activation and self-cleavage of the ribozyme molecules. Vesicles composed of these amphiphiles grew spontaneously through osmotically driven competition between vesicles, and further modification of the membrane composition allowed growth following mixed micelle addition. Our results show that membranes made from simple amphiphiles can form vesicles that are stable enough to retain encapsulated RNAs in the presence of divalent cations, yet dynamic enough to grow spontaneously and allow the passage of $\mathrm{Mg}^{2+}$ and mononucleotides without specific macromolecular transporters. This combination of stability and dynamics is critical for building model protocells in the laboratory and may have been important for early cellular evolution.
\end{abstract}

\section{Introduction}

The ability to evolve through the combined effects of inherited variation and natural selection is the unifying principle of biology. The most elementary cellular system capable of Darwinian evolution requires two components: a self-replicating informational molecule, such as an RNA polymerase ribozyme ("replicase"), and a mechanism for spatial localization such as compartmentalization. Without compartmentalization or some other mechanism for restricting the diffusion of the genetic material, a superior mutant replicase would act to propagate unrelated sequences more efficiently, while having no effect on its own fitness. The physical proximity of related sequences, which can be readily maintained by the random segregation of sequences within replicating compartments, is therefore necessary for the evolution of improved replicase activity through natural selection. ${ }^{1-6}$ Membranes provide the major mechanism for compartmentalization in modern biology and also mediate the chemical fluxes between the cell and its environment.

To construct the simplest possible protocell, the membrane boundary should be capable of growth and division without

(1) Szathmary, E.; Demeter, L. J. Theor. Biol. 1987, 128, 463-486.

(2) Hogeweg, P.; Takeuchi, N. Origins Life Evol. Biosphere 2003, 33, 375403 .

(3) Szabo, P.; Scheuring, I.; Czaran, T.; Szathmary, E. Nature 2002, 420, 340343.

(4) Wade, M. J. Proc. Natl. Acad. Sci. U.S.A. 1976, 73, 4604-4607.

(5) Wilson, D. S. Proc. Natl. Acad. Sci. U.S.A. 1975, 72, 143-146.

(6) Szostak, J. W.; Bartel, D. P.; Luisi, P. L. Nature 2001, 409, 387-390.

10.1021/ja051784p CCC: $\$ 30.25$ @ 2005 American Chemical Society complex biochemical machinery and should allow the entry of ions and small substrates by passive diffusion. To have potential prebiotic relevance, the membrane should also be formed from chemicals that can be synthesized abiotically. Fatty acids are simple amphiphiles that form bilayer membrane vesicles when the solution $\mathrm{pH}$ is near the apparent $\mathrm{p} K_{\mathrm{a}}$ of the membraneincorporated fatty acid. ${ }^{7,8}$ They can be synthesized under a variety of conditions, ${ }^{9,10}$ including simulated hydrothermal vent chemistry, ${ }^{12}$ and have been detected in carbonaceous chondrite meteorites. ${ }^{13,14}$ Clay surfaces that catalyze RNA polymerization also promote the self-assembly of fatty acid micelles into vesicles, suggesting a route for enhancing RNA encapsulation by colocalizing vesicles and RNA. ${ }^{15,16}$

In addition to their chemical simplicity, fatty acid membranes have dynamic properties that are not exhibited by phospholipid

(7) Small, D. M. In The physical chemistry of lipids: from alkanes to phospholipids; Small, D. M., Ed.; Plenum Press: New York, 1986; pp 285343.

(8) Gebicki, J. M.; Hicks, M. Nature 1973, 243, 232-234.

(9) Allen, W. V.; Ponnamperuma, C. Curr. Mod. Biol. 1967, 1, 24-28.

(10) Yuen, G. U.; Lawless, J. G.; Edelson, E. H. J. Mol. Evol. 1981, 17, 4347.

(11) Reference deleted in proof.

(12) McCollom, T. M.; Ritter, G.; Simoneit, B. R. Origins Life Evol. Biosphere 1999, 29, 153-166.

(13) Yuen, G. U.; Kvenvolden, K. A. Nature 1973, 246, 301-303.

(14) Deamer, D. W. Nature 1985, 317, 792-794.

(15) Ferris, J. P.; Ertem, G. Science 1992, 257, 1387-1389.

(16) Hanczyc, M. M.; Fujikawa, S. M.; Szostak, J. W. Science 2003, 302, 618622 .

J. AM. CHEM. SOC. 2005, 127, 13213-13219 a 13213 
membranes. For example, fatty acid vesicles show autocatalytic growth, ${ }^{17,18}$ and they can undergo repeated cycles of growth and division in the laboratory. ${ }^{16}$ These vesicles can also exhibit a primitive form of competition for limited resources, as vesicles encapsulating a high concentration of RNA grow larger at the expense of empty vesicles; this is referred to below as the exchange pathway for growth. ${ }^{19}$ Under certain conditions, growth can drive the formation of a transmembrane $\mathrm{pH}$ gradient, thereby storing energy for several hours. ${ }^{20}$ These protocellular behaviors are facilitated by the fast time scales of monomermicelle-vesicle transitions and the relatively small energetic barriers between these phases, ${ }^{21}$ as compared to phospholipid membranes, which do not share these dynamic properties.

The major disadvantage of using fatty acid membranes to build protocells is their instability under the ionic conditions necessary for catalytic RNA activity. For example, decanoic acid vesicles aggregate at moderate concentrations of monovalent ions $(\sim 0.2 \mathrm{M} \mathrm{NaCl})$, and divalent cations cause aggregation and precipitation even at quite low concentrations $(<1.5 \mathrm{mM}$ $\mathrm{MgCl}_{2}$, or 1:65 ratio of cation to lipid). ${ }^{22}$ This is an important problem because divalent cations are often required for the formation of tertiary contacts in RNA folding and also commonly participate directly in the catalytic mechanism. ${ }^{23,24}$ Consequently, the activity of many ribozymes, such as the hammerhead ribozyme, is highly dependent on divalent cation concentration. ${ }^{25,26}$ For a protocell to use RNA-based biochemistry, vesicle membranes must be stable under conditions enabling ribozyme activity. We therefore sought to encapsulate catalytically active RNA in simple vesicles that were stable and capable of growth.

The addition of fatty acid glycerol esters stabilizes fatty acid vesicles in the presence of ionic solutes. ${ }^{22,27}$ Although a variety of cations can be utilized by ribozymes, we focused on $\mathrm{Mg}^{2+}$ because of its common use by ribozymes and its abundance on the earth, particularly in seawater. We characterized the growth properties, $\mathrm{Mg}^{2+}$ tolerance, and $\mathrm{Mg}^{2+}$ permeability of such mixed composition vesicles. By varying the composition of mixed vesicles, we were able to increase the tolerance of vesicles to $\mathrm{Mg}^{2+}$ and to demonstrate that $\mathrm{Mg}^{2+}$ could rapidly enter vesicles by passive diffusion. Remarkably, the presence of $\mathrm{Mg}^{2+}$ increased the permeability of the membrane to small, negatively charged solutes such as nucleotides. On the other hand, vesicle growth by the exchange pathway was slowed, and vesicle growth following micelle addition was only possible after further modification of the membrane composition. Finally, we encapsulated a hammerhead ribozyme in mixed vesicles and showed that the ribozyme is active under conditions consistent with vesicle stability and growth.

(17) Walde, P.; Wick, R.; Fresta, M.; Mangone, A.; Luisi, P. L. J. Am. Chem. Soc. 1994, 116, 11649-11654.

(18) Berclaz, N.; Muller, M.; Walde, P.; Luisi, P. L. J. Phys. Chem. B 2001, $105,1056-1064$

(19) Chen, I. A.; Roberts, R. W.; Szostak, J. W. Science 2004, 305, 14741476.

(20) Chen, I. A.; Szostak, J. W. Proc. Natl. Acad. Sci. U.S.A. 2004, 101, 79657970.

(21) Chen, I. A.; Szostak, J. W. Biophys. J. 2004, 87, 1-11.

(22) Monnard, P. A.; Apel, C. L.; Kanavarioti, A.; Deamer, D. W. Astrobiology 2002, 2, 139-152.

(23) Draper, D. E.; Misra, V. K. Nat. Struct. Biol. 1998, 5, 927-930.

(24) Misra, V. K.; Draper, D. E. J. Mol. Biol. 2002, 317, 507-521.

(25) Inoue, A.; Takagi, Y.; Taira, K. Magn. Reson. 2003, 16, 210-217.

(26) Sreedhara, A.; Cowan, J. A. Biometals 2002, 15, 211-223.

(27) Monnard, P. A.; Deamer, D. W. Methods Enzymol. 2003, 372, 133-151.

\section{Materials and Methods}

Materials. Myristoleic acid (C14:1) and glycerol 1-monomyristoleate (i.e., monomyristolein, the glycerol ester of myristoleic acid) were purchased from NuChek Prep (Elysian, MN). Pyrene was from Fluka (Buchs SG, Switzerland); N-(7-nitrobenz-2-oxa-1,3-diazol-4-yl)-1,2dihexadecanoyl-sn-glycero-3-phosphoethanolamine (NBD-PE), Lissamine rhodamine B 1,2-dihexadecanoyl-sn-glycero-3-phosphoethanolamine (Rh-DHPE), calcein, and mag-fura-2 (tetrapotassium salt) were from Molecular Probes (Eugene, OR). GlycoBlue was purchased from Ambion, Inc. (Austin, TX), and RNasin was from Promega (Madison, WI). RNA labeled with fluorescein (5'-6-FAM-AAAAAAAAAA-3') was synthesized at the W. M. Keck Facility at Yale University. All other chemicals were purchased from Sigma-Aldrich (St. Louis, MO).

Preparation of Micelles and Vesicles. Micelles were prepared by dissolving neat myristoleic acid oil in 1 equiv of $\mathrm{NaOH}$ solution $(80$ $\mathrm{mM}$ ), as described. ${ }^{16}$ Vesicles $100 \mathrm{~nm}$ in diameter were prepared by resuspending 1 equiv of the oil in $0.2 \mathrm{M}$ bicine buffer, $\mathrm{pH} 8.5$, to which 0.5 equiv of $\mathrm{NaOH}$ had been added (resulting in a final $\mathrm{pH}$ of 8.5). Resuspension was followed by several freeze-thaw cycles and extrusion to $100 \mathrm{~nm}$ diameter using the Mini-Extruder system (Avanti Polar Lipids, Inc.), as described. ${ }^{20}$ Mixed composition micelles and vesicles were prepared by mixing the appropriate neat oils before resuspension. Mixed micelles were used within $10 \mathrm{~min}$ of preparation. Vesicles labeled by the FRET dyes (NBD-PE and Rh-DHPE) were prepared by mixing the dyes with fatty acid/ester in methanol, and then removing the solvent by rotary evaporation before resuspension. ${ }^{19}$

Encapsulation of RNA or water-soluble fluorescent dyes was achieved by mixing the solute with the resuspension buffer before adding the oil. Vesicles were purified from unencapsulated solutes on a gravity-flow size exclusion column (Sepharose 4B). The fluorescent dyes $(\leq 1 \mathrm{kD})$ and RNA $(19 \mathrm{kD})$ used in these experiments elute at the low molecular weight range of the resin $(30 \mathrm{kD})$, while vesicles (100 $\mathrm{nm}$ in diameter) elute with the void volume. Purification and dilution buffers contained a concentration of amphiphiles approximately equal to the critical aggregate concentration, to avoid disintegration of the vesicles.

Vesicle Growth. Vesicles labeled with FRET dyes were diluted to $\sim 3 \mathrm{mM}$ amphiphile and added to a cuvette. Growth from addition of micelles was initiated by adding micelles from an $80 \mathrm{mM}$ stock solution, with mixing by pipetting for $\sim 5 \mathrm{~s}$. FRET was measured using the fluorescence ratio between donor $\left(\lambda_{\mathrm{em}} 530 \mathrm{~nm}\right)$ and acceptor $\left(\lambda_{\mathrm{em}} 586\right.$ $\mathrm{nm}$ ) dyes, with excitation at $430 \mathrm{~nm}$, as described. ${ }^{16}$ To convert FRET signal into relative surface area, a standard curve was prepared for each vesicle composition (Figures S1, S2). Growth by intermembrane transfer of amphiphiles from empty vesicles to vesicles encapsulating tRNA was performed as described previously, ${ }^{19}$ with the addition of $3.2 \mathrm{mM}$ $\mathrm{MgCl}_{2}$ to the reaction buffer containing $2 \mathrm{mM}$ amphiphile. The concentration of free $\mathrm{Mg}^{2+}$ in this solution was $2 \mathrm{mM}$, as measured by mag-fura-2 fluorescence.

Dye Leakage Assay. Extruded vesicles encapsulating calcein or ${ }^{3} \mathrm{H}-$ UMP were added to a small volume of a stock solution of $\mathrm{MgCl}_{2}(100$ $\mathrm{mM})$ to achieve the desired concentration of $\mathrm{Mg}^{2+}$. To determine the extent of dye leakage, vesicles were separated from free dye by sizeexclusion chromatography as described above. The integrated fluorescence intensity of each peak was determined by summing the fluorescence intensity of the fractions, as measured on a SpectraMax Gemini EM (Molecular Devices). For vesicles of this size $(\sim 100 \mathrm{~nm})$, the concentration of vesicles was low enough ( $<10 \mathrm{mM}$ lipid) to avoid effects on the fluorescence from turbidity. Levels of free dye $>6 \%$ were reliably detectable as leakage. Radioactivity was measured on a Beckman LS 6500 scintillation counter. For time courses, the percent of free dye in the initial time point was used as the background and subtracted from subsequent time points. Calcein fluorescence was measured at $\lambda_{\mathrm{ex}} 415 \mathrm{~nm}, \lambda_{\mathrm{em}} 600 \mathrm{~nm}$; when appropriate, values were 
corrected for self-quenching using a standard curve. ${ }^{16}$ Initial rates of leakage were determined by fitting a straight line to the data for leakage over time.

$\mathbf{M g}^{2+}$ Assays. Free $\mathrm{Mg}^{2+}$ concentration was measured using the fluorescent probe mag-fura- $2 . \mathrm{Mg}^{2+}$ concentration was related to the ratio of the fluorescence intensity at $\lambda_{\mathrm{ex}} 340 \mathrm{~nm}$ and $\lambda_{\mathrm{ex}} 370 \mathrm{~nm}$ (at constant $\lambda_{\mathrm{em}} 500 \mathrm{~nm}$ ) through a standard curve prepared with varying concentrations of $\mathrm{MgCl}_{2}$ in $0.2 \mathrm{M}$ bicine, $\mathrm{pH}$ 8.5. To determine $\mathrm{Mg}^{2+}$ permeability, vesicles containing encapsulated mag-fura- 2 were diluted to $4 \mathrm{mM}$ amphiphile and mixed by stopped-flow with $1 / 25$ volume of $50 \mathrm{mM} \mathrm{MgCl} 2$ (final $\left[\mathrm{Mg}^{2+}\right]=2 \mathrm{mM}$ ), as described. ${ }^{21}$ Because the counter-transport of $\mathrm{Na}^{+}$, required for charge neutrality, is fast relative to the transport of $\mathrm{Mg}^{2+},{ }^{20}$ the $\mathrm{Mg}^{2+}$ permeability coefficient was calculated by $P=k^{*} V / A$, where $k$ is the first-order rate constant, and $V$ and $A$ are the volume and surface area of the vesicle, respectively.

Characterization of Aggregates and Vesicles. Hydrodynamic diameter was estimated by dynamic light scattering, as described. ${ }^{16}$ The pyrene excimer/monomer ratio was determined from the ratio of fluorescence intensity at $\lambda_{\mathrm{em}} 374 \mathrm{~nm}$ (monomer) and $\lambda_{\mathrm{em}} 470 \mathrm{~nm}$ (excimer), as described. ${ }^{21}$ Amphiphile samples were prepared with 0.5 mol \% pyrene.

Hammerhead Ribozyme RNA. The transcription template for the hammerhead ribozyme N15min7 (5'- GGGACGCAGTTTCGCTTAGCTCATCAGAGTAAATTCCTTTCGGAATTTAC TGACTGCGTCCCTATAGTGAGTCGTATTACAGATC-3') was PCR amplified using the primers (5'-GATCTGTAATACGACTCAC-3' and $5^{\prime}$-GGGACGCAGTTTCGCTTAG-3') for 20 cycles. The PCR product was purified using agarose gel electrophoresis, ethanol precipitated, dissolved, and stored in $10 \mathrm{mM}$ Tris- $\mathrm{Cl}, \mathrm{pH} 8.5$.

RNA was transcribed from double-stranded N15min7 template by T7 RNA polymerase in a solution containing $0.5 \mathrm{mM}$ NTPs, $\sim 20 \mu \mathrm{Ci}$ $\alpha$ - ${ }^{32} \mathrm{P}-\mathrm{UTP}, 40 \mathrm{mM}$ Tris- $\mathrm{HCl}, \mathrm{pH}$ 7.9, $6 \mathrm{mM} \mathrm{MgCl} 2,2 \mathrm{mM}$ spermidine, $10 \mathrm{mM}$ DTT, and $0.2 \mathrm{U} / \mu \mathrm{L}$ RNasin. The reaction also included 25 $\mu \mathrm{M}$ of two oligonucleotides complementary to the ribozyme sequence, to block ribozyme self-cleavage during transcription (5'-TCGCTTAGCTCATCAG-3' and 5'-GGAATTTACTGACTGC- $3^{\prime}$ ). ${ }^{28}$ Transcribed RNA was purified by denaturing PAGE, ethanol precipitated, dissolved in water, and stored at $-80^{\circ} \mathrm{C}$.

Hammerhead Ribozyme Assay. Cleavage reactions were begun by the addition of $\mathrm{MgCl}_{2}$. The reaction was stopped at each time point by removing an aliquot and adding $1.1-2.3$ volumes of $10 \mathrm{mM}$ Tris$\mathrm{Cl}, \mathrm{pH} 7.5$, containing 3-14 mM EDTA. For encapsulated reactions, the amphiphile concentration was $\sim 15 \mathrm{mM}$ and the RNA concentration was $40-300 \mathrm{nM}$ (less than one molecule per vesicle on average). Vesicles were disrupted by the addition of $0.3 \%$ Triton X-100, and the RNA was precipitated in $0.3 \mathrm{M}$ sodium acetate, $\mathrm{pH} 7,73 \%$ ethanol, with $10 \mu \mathrm{g}$ of GlycoBlue. Pellets were resuspended in formamide loading buffer and resolved by denaturing PAGE. Cleavage products were quantitated by phosphorimage analysis of the dried gel. The extent of cleavage observed before addition of $\mathrm{MgCl}_{2}(t=0)$ was subtracted from subsequent time points.

Fluorescence Microscopy. Vesicles were prepared by mixing MA: GMM:dodecane (2:1:0.3) oil with buffer consisting of $0.2 \mathrm{M}$ bicine, $\mathrm{pH} 8.5,3 \mathrm{mM} \mathrm{MgCl}_{2}$, and $40 \mathrm{nM} \mathrm{N} 15 \min 7$ (final amphiphile concentration $=20 \mathrm{mM}$ ). Vesicle suspensions were allowed to equilibrate for at least $1 \mathrm{~h}$ before staining with $10 \mathrm{mM}$ Rhodamine 6G $\left(\lambda_{\max , \mathrm{ex}}=528 \mathrm{~nm} ; \lambda_{\max , \mathrm{em}}=551 \mathrm{~nm}\right)$ for microscopy. Conventional epifluorescence images were collected using a Zeiss Axioplan 2 microscope $(100 \times$ objective lens; rhodamine filter). Confocal images were collected using a Leica TCS SP confocal laser scanning microscope equipped with $\mathrm{Ar}, \mathrm{Ar}-\mathrm{Kr}$, and $\mathrm{He}-\mathrm{Ne}$ lasers (100x objective lens; $514 \mathrm{~nm}$ laser line).

(28) Salehi-Ashtiani, K.; Szostak, J. W. Nature 2001, 414, 82-84.
Table 1. $\mathrm{MgCl}_{2}$ Tolerance of Simple Vesicles

\begin{tabular}{ccc}
\hline MA:GMM & $\begin{array}{c}{\left[\mathrm{MgCl}_{2}\right]} \\
\text { tolerated, } \\
\text { assayed by } \\
\text { dye leakage } \\
\text { ratio }\end{array}$ & $\begin{array}{c}\left.[\mathrm{MgCl})_{2}\right] \text { at } \\
\text { turbidity } \\
\text { change } \\
(\mathrm{mM})\end{array}$ \\
\hline $1: 0$ & 0.5 & 1 \\
$4: 1$ & 2 & 3 \\
$2: 1$ & 4 & 6 \\
\hline
\end{tabular}

$a$ Dye leakage was assessed $<1 \mathrm{~h}$ after addition of $\mathrm{MgCl}_{2}$, and onset of leakage defined the maximum $\left[\mathrm{MgCl}_{2}\right]$ tolerated. ${ }^{b}$ Turbidity change was visible as a sudden increase in the opacity of the solution.

\section{Results and Discussion}

Effect of $\mathrm{Mg}^{2+}$ on the Stability and Permeability of Simple Vesicles. We assessed the stability of vesicles composed of myristoleic acid (MA) and glycerol monomyristoleate (GMM) in the presence of $\mathrm{Mg}^{2+}$ by monitoring the retention of encapsulated dye and macroscopic turbidity changes. Pure MA vesicles showed low $\mathrm{Mg}^{2+}$ tolerance, but vesicles of mixed composition, MA:GMM (2:1), showed increased stability in the presence of $\mathrm{Mg}^{2+}$, as previously reported on the basis of light microscopy. ${ }^{22}$ An intermediate composition of MA:GMM (4: 1) showed intermediate stability (Table 1 ). Higher proportions of GMM led to the appearance of oil droplets mixed with vesicles.

To determine whether vesicles exposed to relatively high concentrations of $\mathrm{MgCl}_{2}$ are only transiently destabilized by the sudden addition of $\mathrm{MgCl}_{2}$, we followed the leakage of encapsulated calcein over time. Dye leakage continued to increase over the course of at least 1 day (Figure 1A,B), indicating that the vesicles remained permeabilized throughout the experiment. The initial rate of dye leakage from MA:GMM (2:1) vesicles increased by a factor of 27 in the presence of $4 \mathrm{mM} \mathrm{Mg}^{2+}$. To determine whether this enhanced permeability was due to largescale membrane destabilization by $\mathrm{Mg}^{2+}$, we encapsulated a fluorescently labeled RNA decamer in vesicles exposed to 4 $\mathrm{mM} \mathrm{Mg}^{2+}$. We expected that large-scale membrane defects would cause RNA leakage at a rate similar to small molecule leakage, but no RNA leakage was detected after 19 h (Figure $1 C) .{ }^{3} \mathrm{H}$-UMP showed a 4 -fold permeability enhancement in the presence of $4 \mathrm{mM} \mathrm{Mg}^{2+}$ (Figure 1D). Thus, exposure to $\mathrm{Mg}^{2+}$ increased the permeability of an RNA mononucleotide but not of RNA itself, perhaps by neutralizing the negative charge and/or stabilizing the interaction between the solute and small-scale transient defects in the membrane. ${ }^{29}$ Even so, more than $95 \%$ of encapsulated calcein was retained in MA:GMM (2:1) vesicles for at least $3 \mathrm{~h}$. This is much longer than the hammerhead ribozyme cleavage reactions described below, which were completed within a few minutes.

Because we wished to eventually measure the activity of encapsulated RNA, we also determined the permeability of $\mathrm{Mg}^{2+}$ through the vesicle membrane. We encapsulated magfura-2, ${ }^{30}$ a magnesium-sensitive fluorescent dye (Figure 2A), in MA:GMM vesicles $(2: 1)$ and added $\mathrm{MgCl}_{2}$ using a stoppedflow device. The internal concentration of $\mathrm{Mg}^{2+}$ equilibrated within several seconds (permeability coefficient $=2 \times 10^{-7}$

(29) Chakrabarti, A. C.; Deamer, D. W. Biochim. Biophys. Acta 1992, 1111 $171-177$.

(30) Watanabe, M.; Konishi, M. Pfluegers Arch. 2001, 442, 35-40. 

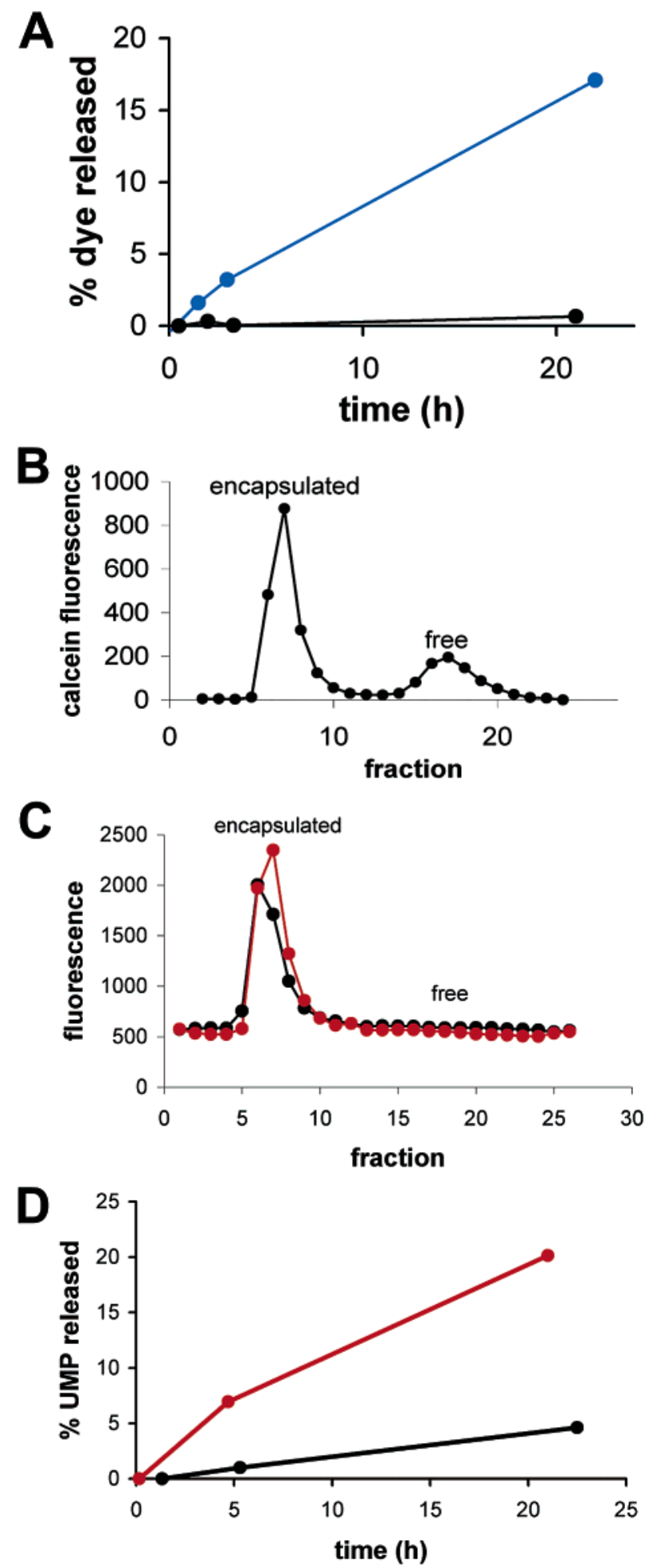

Figure 1. Leakage from MA:GMM vesicles (2:1) in $0.2 \mathrm{M}$ bicine, $\mathrm{pH}$ $8.5,4 \mathrm{mM} \mathrm{MgCl} 2$. (A) Vesicles were initially purified away from unencapsulated calcein, and dye leakage was measured over time with (blue) or without (black) the addition of $4 \mathrm{mM} \mathrm{MgCl}_{2}$. (B) Calcein leakage assayed by size-exclusion chromatography after $22 \mathrm{~h}$ in the presence of $4 \mathrm{mM}$ $\mathrm{MgCl}_{2}$. (C) RNA leakage assayed by size-exclusion chromatography after $19 \mathrm{~h}$, with (red) or without (black) the addition of $4 \mathrm{mM} \mathrm{MgCl}_{2}$. (D) Vesicles encapsulating $0.1 \mathrm{mM} 5^{\prime}$-UMP and a trace amount of ${ }^{3} \mathrm{H}$-UMP were initially purified, and then leakage of ${ }^{3} \mathrm{H}-\mathrm{UMP}$ was measured over time, with (red) or without (black) the addition of $4 \mathrm{mM} \mathrm{MgCl}_{2}$.

$\mathrm{cm} / \mathrm{s}$ ) to $1.4 \mathrm{mM}$, a concentration lower than the added concentration (2 mM; Figure 2B). Because MA is partially negatively charged at $\mathrm{pH} 8.5$, it may associate with $\mathrm{Mg}^{2+}$,

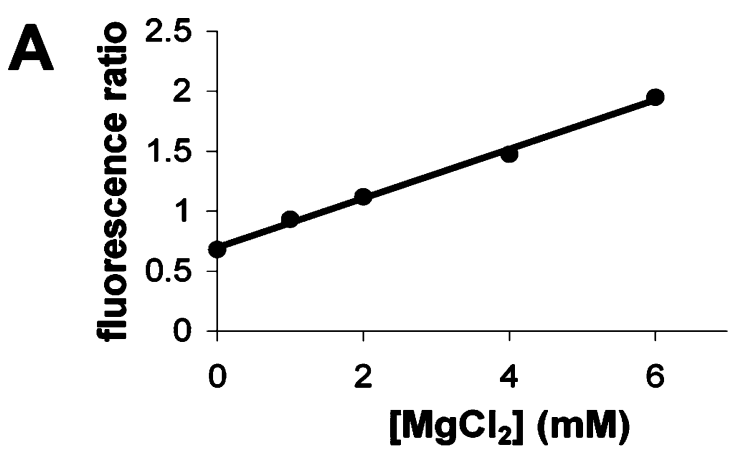

B
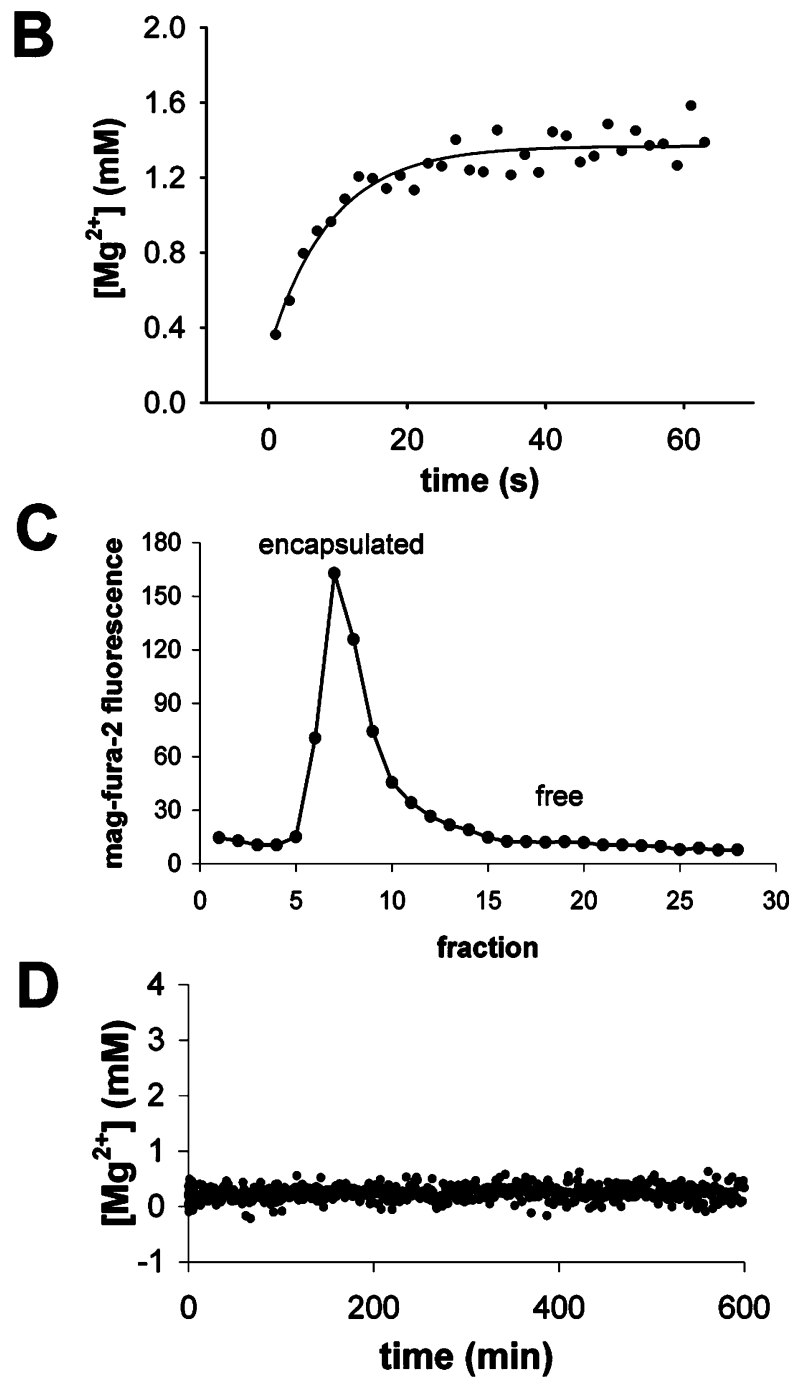

Figure 2. $\mathrm{Mg}^{2+}$ permeability in MA:GMM vesicles (2:1). (A) Standard curve of mag-fura-2 fluorescence ratio as a function of $\left[\mathrm{Mg}^{2+}\right]$ in $0.2 \mathrm{M}$ bicine, $\mathrm{pH}$ 8.5. The solid line is a linear regression fit. $\mathrm{MgCl}_{2}$ was added to a final concentration of $2 \mathrm{mM}$, by stopped-flow mixing, to MA:GMM (2: 1) vesicles (B) or POPC vesicles (D) encapsulating mag-fura-2. The internal concentration of $\mathrm{Mg}^{2+}$ at each time point was calculated from the standard curve. The solid line (B) indicates a curve fit to a single-exponential equation, where $k=0.11 \mathrm{~s}^{-1}$. (C) Size-exclusion chromatography shows that no mag-fura-2 dye has leaked out of the MA:GMM vesicles after equilibration of $\mathrm{Mg}^{2+}$.

thereby reducing the amount of free $\mathrm{Mg}^{2+}$ detected by the magfura-2 dye. Using size-exclusion chromatography, we verified that $<5 \%$ of encapsulated mag-fura- 2 leaked from vesicles after 30 min of exposure to $2 \mathrm{mM} \mathrm{Mg}^{2+}$ (Figure 2C), consistent with the results obtained for calcein leakage. When we mixed phospholipid (POPC) vesicles with $\mathrm{MgCl}_{2}$, we saw no detectable 
change in the internal $\mathrm{Mg}^{2+}$ concentration over several hours (Figure 2D), demonstrating that equilibration of both $\mathrm{Mg}^{2+}$ and mag-fura-2 across POPC membranes is quite slow.

Growth of $\mathbf{M g}^{\mathbf{2}+}$-Tolerant Vesicles. Although the addition of GMM to MA vesicles increased their tolerance for $\mathrm{Mg}^{2+}$, we suspected that the increase in the stability of the vesicles might come at the expense of dampened dynamic behaviors, such as growth, that rely on the rapid insertion and dissociation of molecules from the membrane. Growth of the surface area of vesicles can be monitored using nonexchanging FRET dyes, whose fluorescence depends on the surface density of the dyes. ${ }^{16,31,32}$ We have previously studied the growth of osmotically swollen vesicles due to intermembrane transfer of amphiphiles from empty vesicles. While transfer was slower in MA:GMM (2:1) membranes, the total amount of transfer was comparable in MA:GMM (2:1) and pure fatty acid membranes. ${ }^{19}$ To determine whether $\mathrm{Mg}^{2+}$ affected the intermembrane transfer of amphiphiles, we measured the transfer between MA:GMM (2:1) vesicles (2 $\mathrm{mM}$ amphiphile) in the presence of $3.2 \mathrm{mM}$ $\mathrm{MgCl}_{2}\left(2 \mathrm{mM}\right.$ free $\left.\mathrm{Mg}^{2+}\right)$. The rate $\left(k=0.05 \mathrm{~min}^{-1}\right)$ and amount of transfer $(28 \%)$ were not substantially affected by the presence of $\mathrm{Mg}^{2+}$

Another way to achieve vesicle growth is by the addition of micelles, prepared at high $\mathrm{pH}$, to preformed vesicles buffered at $\mathrm{pH}$ 8.5. When 0.5 equiv of pure fatty acid in micelle form is rapidly added to preformed vesicles, the surface area of preformed vesicles grows by $\sim 50 \%$, indicating a very high yield of incorporation. ${ }^{16,21}$ In contrast, 4:1 MA:GMM vesicles showed only $\sim 35 \%$ growth upon addition of 0.5 equiv of micelles of the same composition. Dynamic light scattering (DLS) indicated that MA:GMM (4:1) micelle solutions contained particles $~ 30$ $\mathrm{nm}$ in diameter, much larger than pure fatty acid micelles (diameter $=3 \mathrm{~nm}) .{ }^{20}$ Aggregation can also be detected by the excimer/monomer ratio of the hydrophobic dye pyrene when present at low molar ratio $(\sim 1: 200)$. When dissolved in small micelles, pyrene is distributed among the separate volumes and exists primarily as a monomer. However, lipid aggregation allows multiple pyrene molecules to share a contiguous volume, forming excimers with a red-shifted fluorescence emission spectrum. ${ }^{33-35}$ Consistent with the DLS data, pyrene fluorescence indicated the presence of large aggregates in MA:GMM (4:1) micelles (Figure 3A).

MA:GMM (2:1) vesicles, which had the greatest magnesium tolerance, showed no growth when micelles of the same composition were added, either rapidly or slowly over $4 \mathrm{~h}$. However, these vesicles were able to grow following the rapid addition of pure fatty acid micelles. Thus, 2:1 MA:GMM micelles (which are also large by the pyrene excimer assay and by DLS) appeared to be unusually stable, perhaps due to the large headgroup of GMM, which may stabilize areas of high curvature in micellar aggregates and which would also provide $\mathrm{H}$-bond donors at high $\mathrm{pH}$. To destabilize these micelles, we added dodecane $(9 \mathrm{~mol} \%)$ to act as a hydrophobic spacer, reducing the preferred curvature and decreasing the surface

(31) Fung, B. K.-K.; Stryer, L. Biochemistry 1978, 17, 5241-5248.

(32) Struck, D. K.; Hoekstra, D.; Pagano, R. E. Biochemistry 1981, 20, 40934099 .

(33) Almgren, M.; Grieser, F.; Thomas, J. K. J. Am. Chem. Soc. 1979, 101, 279-291

(34) Vanderkooi, J. M.; Callis, J. B. Biochemistry 1974, 13, 4000-4006.

(35) Schenkman, S.; Araujo, P. S.; Dijkman, R.; Quina, F. H.; Chaimovich, H. Biochim. Biophys. Acta 1981, 649, 633-647.
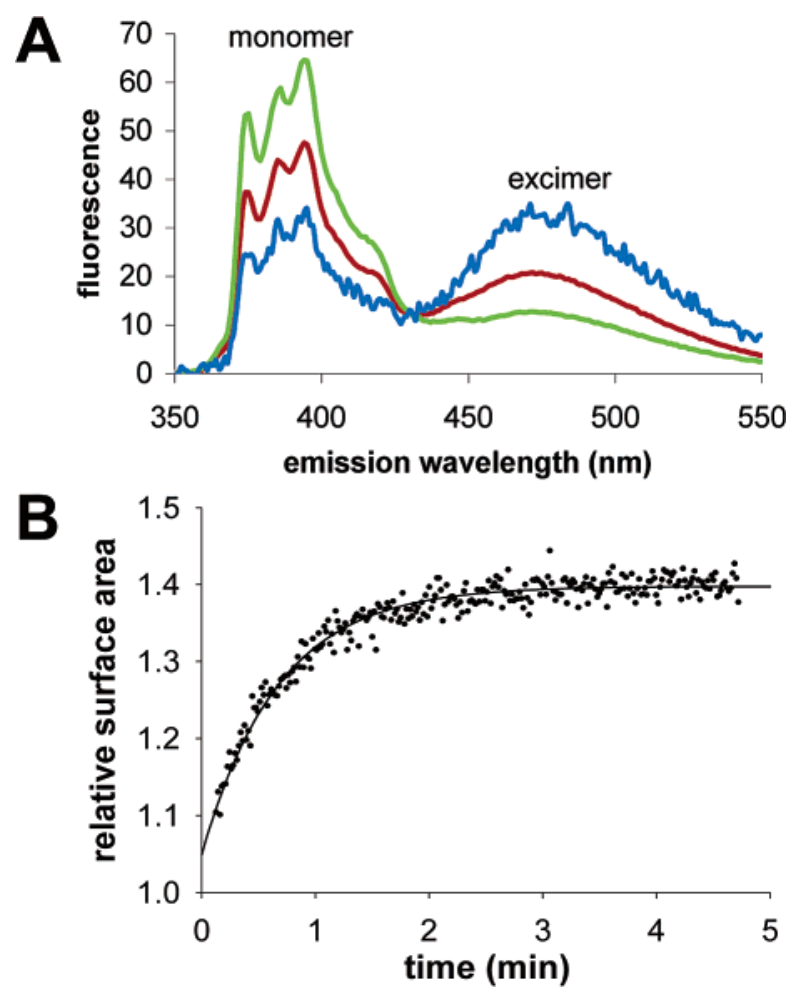

Figure 3. Growth of mixed composition vesicles by micelle incorporation. (A) Pyrene fluorescence shifts from monomer to excimer if aggregates are present. Shown are the spectra of pyrene in pure MA micelles (green), pure MA vesicles (blue), and MA:GMM (4:1) micelles (red). (B) Growth of 2:1:0.3 MA:GMM:dodecane vesicles over time, after addition of 1 equiv of micelles, in $0.2 \mathrm{M}$ bicine, $\mathrm{pH} 8.5,1 \mathrm{mM} \mathrm{MgCl}_{2}$. Relative surface area was determined using the FRET assay. The solid line indicates a curve fit to a single-exponential equation, with $k=1.5 \mathrm{~min}^{-1}$. A similar yield was obtained if 1 equiv of micelles was added at once or in up to five separate aliquots.

charge density. The rapid addition of 0.5 equiv of 2:1:0.3 MA: GMM:dodecane micelles to vesicles of the same composition resulted in $\sim 20 \%$ growth, and the rapid addition of 1 equiv of micelles resulted in $\sim 40 \%$ growth (Figure $3 \mathrm{~B}$ ). The rate and total amount of growth were similar in the presence or absence of $1 \mathrm{mM}$ free $\mathrm{Mg}^{2+}$.

Ribozyme Activity in Simple Vesicles. We determined the activity of a self-cleaving hammerhead ribozyme encapsulated in MA:GMM:dodecane vesicles. The hammerhead ribozyme is widespread in nature and also arises during in vitro selection for self-cleaving RNAs. ${ }^{28,36-38}$ This ribozyme can catalyze both cleavage and ligation of RNAs, ${ }^{39,40}$ activities that may be important for simple RNA-based replicating systems. Furthermore, because of its small size, the hammerhead ribozyme may function robustly under error-prone replication conditions. ${ }^{41}$ $\mathrm{N} 15 \mathrm{~min} 7$ is an artificially evolved 62 nucleotide hammerhead ribozyme, which is cleaved into two fragments (11 and 51 nucleotides) in the presence of $\mathrm{Mg}^{2+} .42$

(36) Blount, K. F.; Uhlenbeck, O. C. Biochem. Soc. Trans. 2002, 30, 11191122.

(37) Stage-Zimmermann, T. K.; Uhlenbeck, O. C. RNA 1998, 4, 875-889.

(38) Vaish, N. K.; Kore, A. R.; Eckstein, F. Nucleic Acids Res. 1998, 26, $5237-$ 5242.

(39) Stage-Zimmermann, T. K.; Uhlenbeck, O. C. Nat. Struct. Biol. 2001, 8 , 863-867.

(40) Dunham, C. M.; Murray, J. B.; Scott, W. G. J. Mol. Biol. 2003, 332, $327-$ 336.

(41) Diener, T. O. Proc. Natl. Acad. Sci. U.S.A. 1989, 86, 9370-9374.

(42) Salehi-Ashtiani, K.; Szostak, J. W., unpublished data. 

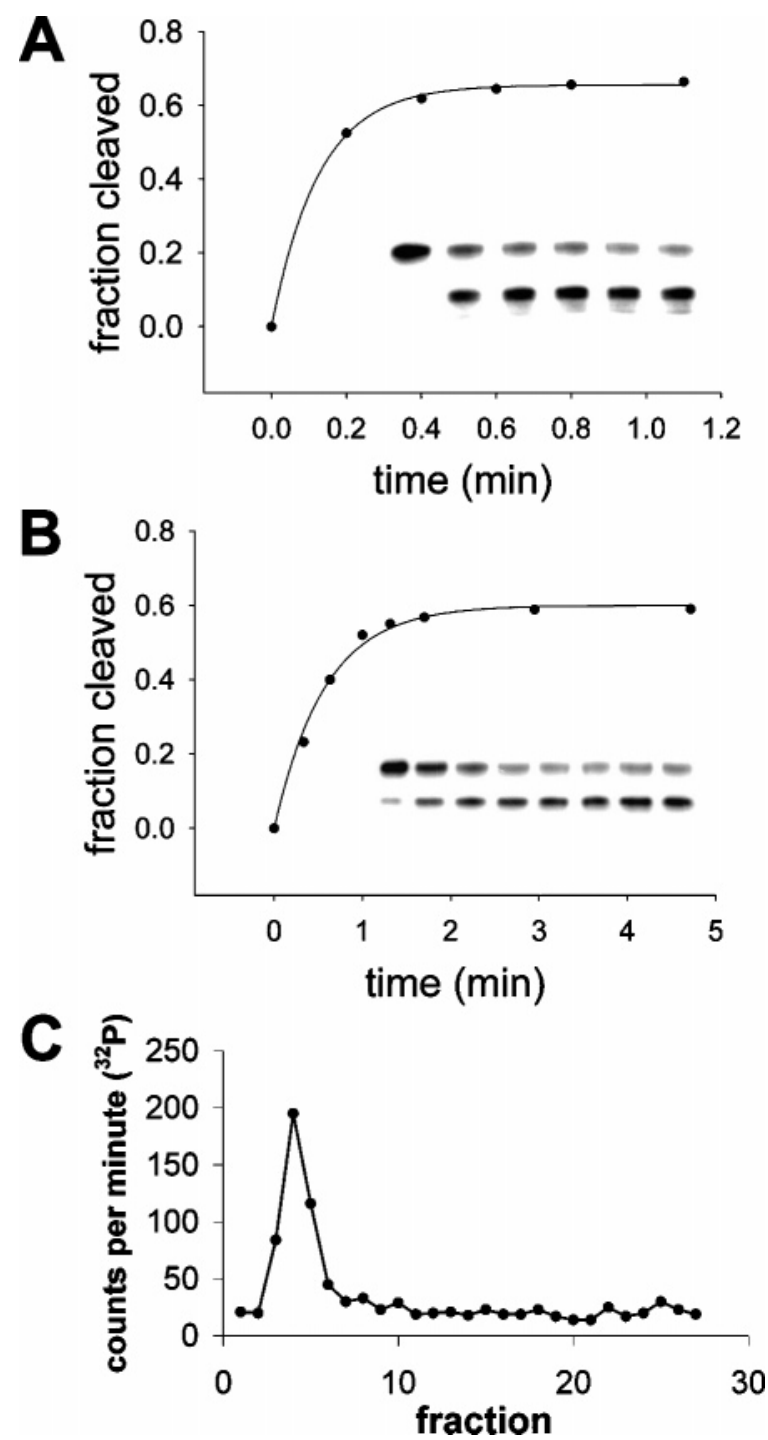

Figure 4. Self-cleavage activity of the hammerhead ribozyme N15min7. The insets show phosphorimages of the assay gels. The top band corresponds to the uncleaved ribozyme; the bottom band is the cleavage product. (A) Unencapsulated ribozyme activity in $0.2 \mathrm{M}$ bicine, $\mathrm{pH} 8.5,4 \mathrm{mM} \mathrm{MgCl} 2$ Time points, from left to right: 0 (no $\mathrm{MgCl}_{2}$ ), $0.2,0.4,0.6,0.8,1.1 \mathrm{~min}$. The solid line indicates a curve fit to a single-exponential equation, $y=$ $a\left(1-e^{-k x}\right)$, where the extent of cleavage $a=0.66$, and the observed rate constant $k=7.9 \mathrm{~min}^{-1}$. (B) Activity of ribozymes encapsulated in 2:1:0.3 MA:GMM:dodecane vesicles ( $\sim 15 \mathrm{mM}$ amphiphile), in $0.2 \mathrm{M}$ bicine, $\mathrm{pH}$ $8.5,4 \mathrm{mM} \mathrm{MgCl} 2$. Time points, from left to right: 0 (no $\mathrm{MgCl}_{2}$ ), 0.33 , $0.63,1,1.3,1.7,3,4.7 \mathrm{~min}$. Curve fit: $a=0.6$, and $k=1.7 \mathrm{~min}^{-1}$. (C) Size-exclusion chromatography of MA:GMM:dodecane vesicles shows that all radiolabeled N15min7 RNA remained encapsulated 15 min after the addition of $\mathrm{MgCl}_{2}$.

N15min7 was encapsulated in 2:1:0.3 MA:GMM:dodecane vesicles during amphiphile resuspension. Multiple freeze-thaw cycles, used to equilibrate vesicle formation, did not affect selfcleavage activity. The self-cleavage reaction was initiated by adding $\mathrm{MgCl}_{2}(\leq 4 \mathrm{mM})$, and the extent of self-cleavage was monitored as a function of time (Figure 4A,B). We found that $\sim 60 \%$ of the RNA was cleaved whether the ribozyme was encapsulated or free in solution. The observed first-order rate constant of the encapsulated reaction was reduced 4-fold as compared to the unencapsulated reaction at both 1 and $4 \mathrm{mM}$ added $\mathrm{MgCl}_{2}$ (Table 2). As expected, the rate of the encapsulated reaction in $4 \mathrm{mM}$ added $\mathrm{MgCl}_{2}$ was $\sim 5$-fold higher than that in $1 \mathrm{mM}$ added $\mathrm{MgCl}_{2}$.
Table 2. Hammerhead Cleavage in Vesicles

\begin{tabular}{ccc}
\hline $\begin{array}{c}{\left[\mathrm{MgCl}_{2}\right]} \\
(\mathrm{mM})\end{array}$ & $\begin{array}{c}k_{\text {unencapsulated }} \\
\left(\mathrm{min}^{-1}\right)\end{array}$ & $\begin{array}{c}k_{\text {encapsulated }} \\
\left(\mathrm{min}^{-1}\right)\end{array}$ \\
\hline 1 & 1.3 & 0.4 \\
4 & 7.9 & 1.7 \\
\hline
\end{tabular}
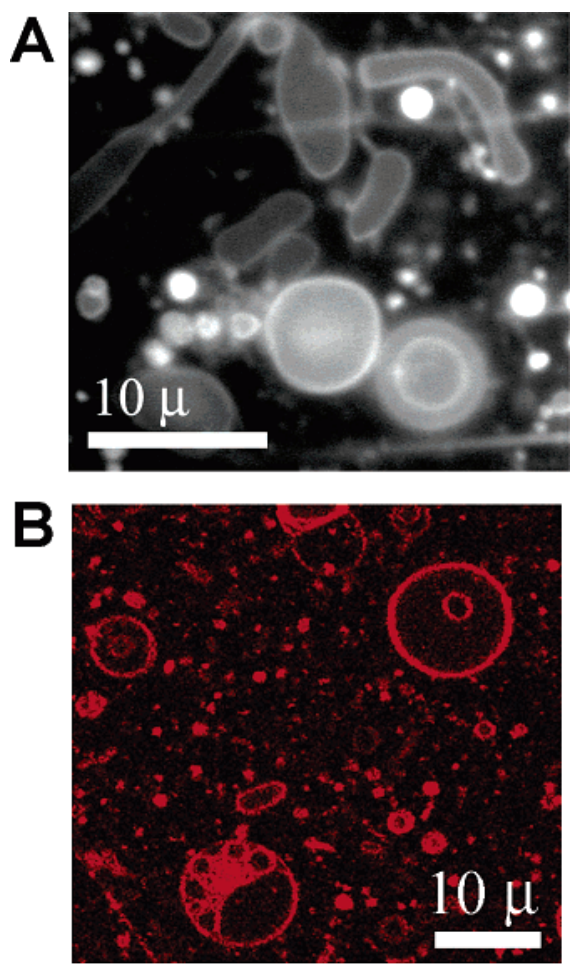

Figure 5. Fluorescence microscopy of 2:1:0.3 MA:GMM:dodecane vesicles containing hammerhead ribozyme in the presence of $3 \mathrm{mM} \mathrm{MgCl} 2$, prior to extrusion. Membranes were stained using Rhodamine $6 \mathrm{G}$ for visualization by (A) epifluorescence or (B) laser scanning confocal microscopy. The images shown are from different fields of view.

This decreased rate of self-cleavage of the encapsulated ribozyme may be partly due to the time scale of $\mathrm{Mg}^{2+}$ permeation into GMM-MA-dodecane vesicles $\left(k \approx 1 \mathrm{~min}^{-1}\right)$, particularly in $4 \mathrm{mM} \mathrm{MgCl}$. However, for the encapsulated ribozyme in $1 \mathrm{mM} \mathrm{MgCl}_{2}$, the rate of $\mathrm{Mg}^{2+}$ entry is faster than the observed self-cleavage, indicating that $\mathrm{Mg}^{2+}$ entry was not the rate-limiting step in this case. The decrease in free $\mathrm{Mg}^{2+}$ concentration $\left(K_{\mathrm{d}} \approx 10 \mathrm{mM}\right.$ amphiphile, considering both the inner and the outer leaflets of the bilayer), as determined by mag-fura-2 fluorescence, accounts for about one-half of the observed decrease in rate. To confirm that the observed selfcleavage activity reflected encapsulated ribozyme, rather than ribozyme adsorbed to the membrane, N15min7 RNA was added to the exterior of vesicles after extrusion but before purification. After purification by size-exclusion chromatography, these preparations contained $<3 \%$ of the radioactivity of the encapsulated reaction, indicating that only a small amount of RNA was adsorbed to the membrane. We also used size-exclusion chromatography to confirm that the ribozyme still co-purified with vesicles after the self-cleavage reaction (Figure 4C).

We confirmed that the 2:1:0.3 MA:GMM:dodecane mixture formed vesicles in the presence of $\mathrm{Mg}^{2+}$ and RNA by fluorescence microscopy before extrusion (Figure 5). DLS of these vesicles after extrusion indicated an average particle diameter of $65 \mathrm{~nm}$, similar to the size of extruded vesicles made 
from myristoleic acid alone. ${ }^{16}$ Furthermore, self-cleavage of $\mathrm{N} 15 \mathrm{~min} 7$ was neither catalyzed nor inhibited by the presence of vesicles alone. In the absence of $\mathrm{Mg}^{2+}$, no self-cleavage was detected after $30 \mathrm{~min}$, and the self-cleavage rate of unencapsulated $\mathrm{N} 15 \mathrm{~min} 7$ upon addition of $\mathrm{Mg}^{2+}$ was not affected by the presence of vesicles.

Hammerhead ribozymes vary greatly in their $\mathrm{Mg}^{2+}$ requirements. The $\left[\mathrm{Mg}^{2+}\right]_{1 / 2}$ (concentration of $\mathrm{Mg}^{2+}$ corresponding to half-maximal activity) of the N15 construct used in our studies is $\sim 9 \mathrm{mM},{ }^{42}$ and hammerhead ribozymes of biological origin have even lower $\mathrm{Mg}^{2+}$ optima of $<1 \mathrm{mM}^{43}$ Other complex natural ribozymes that function under physiological conditions $(<1 \mathrm{mM})$ have evolved low $\mathrm{Mg}^{2+}$ requirements. ${ }^{44}$ For example, the $\left[\mathrm{Mg}^{2+}\right]_{1 / 2}$ for folding and catalysis of a number of selfsplicing group I introns is $\leq 4 \mathrm{mM} .{ }^{45,46}$ An RNA polymerase ribozyme with a similarly low $\mathrm{Mg}^{2+}$ requirement could function inside MA:GMM vesicles. However, currently available ribozymes with polymerase or ligase activity have much higher $\mathrm{Mg}^{2+}$ requirements. For example, the class I ligase, discovered by in vitro evolution in the presence of high concentrations of $\mathrm{Mg}^{2+}$, has a $\left[\mathrm{Mg}^{2+}\right]_{1 / 2}$ of $70-100 \mathrm{mM},{ }^{47}$ as does a variant that can catalyze limited RNA polymerization. ${ }^{48}$ The discrepancy between the $\mathrm{Mg}^{2+}$ requirement of this ribozyme and the $\mathrm{Mg}^{2+}$ tolerance of the simple vesicles studied here suggests that observing ribozyme polymerase activity inside vesicles that can grow and divide may not be trivial in practice. Further optimization of existing ribozymes, or isolation of new ones, may yield RNA polymerases active at lower $\mathrm{Mg}^{2+}$ concentrations that could be compatible with the vesicles described here. An independent reason for focusing on low to moderate $\mathrm{Mg}^{2+}$ concentrations is that high $\mathrm{Mg}^{2+}$ concentrations promote RNA degradation. ${ }^{49} \mathrm{Mg}^{2+}$-catalyzed RNA degradation is in fact thought to limit the extent of polymerization obtainable by the polymerase derived from the class I ligase. ${ }^{48}$

\section{Conclusions}

We have shown that vesicles composed of chemically simple amphiphiles can be stable, grow, and retain contents in the presence of sufficient $\mathrm{Mg}^{2+}$ to activate encapsulated ribozymes. Because these membranes, unlike phospholipid membranes, are quite permeable to $\mathrm{Mg}^{2+}$, encapsulated ribozymes can be activated by the external addition of $\mathrm{Mg}^{2+}$. Other RNAcatalyzed reactions, including RNA replication, may ultimately be possible within similar vesicles, enabling the experimental construction of evolvable protocells. The permeability of these simple membranes to $\mathrm{Mg}^{2+}$ means that the internal $\mathrm{Mg}^{2+}$ concentration of a population of growing and dividing vesicles

(43) Khvorova, A.; Lescoute, A.; Westhof, E.; Jayasena, S. D. Nat. Struct. Biol. 2003, 10, 708-712.

(44) Grubbs, R. D. Biometals 2002, 15, 251-259.

(45) Luptak, A.; Doudna, J. A. Nucleic Acids Res. 2004, 32, 2272-2280.

(46) Rangan, P.; Masquida, B.; Westhof, E.; Woodson, S. A. Proc. Natl. Acad Sci. U.S.A. 2003, 100, 1574-1579.

(47) Glasner, M. E.; Bergman, N. H.; Bartel, D. P. Biochemistry 2002, 41, $8103-$ 8112 .

(48) Johnston, W. K.; Unrau, P. J.; Lawrence, M. S.; Glasner, M. E.; Bartel, D. P. Science 2001, 292, 1319-1325.

(49) Li, Y.; Breaker, R. R. J. Am. Chem. Soc. 1999, 121, 5364-5372. could be maintained indefinitely, from generation to generation, solely by passive trans-membrane diffusion in the absence of permeases.

Our experiments also illustrate that there are tradeoffs in the search for conditions compatible with both RNA and vesicle replication. While the addition of GMM confers stability on MA vesicles, it also causes a decrease in the yield of growth following micelle addition. This decrease could be partially offset by the addition of another simple component, dodecane. On the other hand, the yield of growth of osmotically swollen vesicles was not affected by the addition of GMM. ${ }^{19}$ Indeed, this mode of growth may be more likely to occur in natural situations, because the source of lipid, empty vesicles, is the same physical phase as the growing vesicles, readily permitting their coexistence.

An unexpected effect of $\mathrm{Mg}^{2+}$ was to increase the permeability of small, negatively charged solutes, including uridine monophosphate. This effect would be advantageous to an encapsulated replicating RNA that was polymerizing nucleic acid monomers into longer strands of RNA. The increase in monomer permeability might enhance polymerization, while the polymeric product would continue to be retained.

Many selective pressures are likely to have influenced the evolution of the phospholipid membranes of modern biology, which are much more stable to divalent cations and can maintain $\mathrm{pH}$ and ionic gradients for long periods. However, the evolution of such membranes would have required the co-evolution of numerous ion and substrate-specific permeases, as well as the biochemical machinery for membrane growth. Our results show that membranes made from simple amphiphiles can be stable enough to retain RNA, yet dynamic enough to grow and allow the spontaneous entry of $\mathrm{Mg}^{2+}$ and mononucleotides. We are continuing to search for membrane compositions with similar dynamic properties, but greater tolerance to $\mathrm{Mg}^{2+}$ and possibly $\mathrm{Ca}^{2+}$ (another abundant divalent cation on earth), as well as ribozyme polymerases active at lower $\mathrm{Mg}^{2+}$ concentrations, with the goal of observing RNA-catalyzed RNA synthesis within model protocell vesicles.

Acknowledgment. We are grateful to Pierre-Alain Monnard, Martin Hanczyc, Shelly Fujikawa, Sheref Mansy, Justin Ichida, Michael Sacerdote, James Carothers, and Andrej Luptak for valuable discussions. We thank Gary Ruvkun and Frederick Ausubel for the use of their microscopes. J.W.S. is an investigator of the Howard Hughes Medical Institute. I.A.C. was supported by the NIH Medical Scientist Training Program (\#T32-GM07753) and an NIH Molecular Biophysics Training Grant (\#T32-GM08313). This work was supported in part by a grant from the NASA Exobiology Program (EXB02-00310018).

Supporting Information Available: Standard curve for FRET signal prepared using 4:1 MA:GMM vesicles (Figure S1) and 2:1 MA:GMM vesicles (Figure S2). This material is available free of charge via the Internet at http://pubs.acs.org.

JA051784P 